\title{
Asenkron Motorun Çalıșma Parametrelerinin SCADA ile İzlenmesinin Tasarımı
}

\author{
Hakan Terzioğlu ${ }^{1 *}$, Abdullah Cem Ağaçayak ${ }^{2}$, Gökhan Yalçın ${ }^{3}$, Süleyman Neşeli ${ }^{4}$ \\ ${ }^{I}$ Department of Electrical and Energy, Konya Technical University, Konya,Turkey (ORCID: 0000-0001-5928-8457) \\ ${ }^{2}$ Department of Electrical and Energy, Konya Technical University, Konya,Turkey (ORCID: 0000-0002-9285-5764) \\ ${ }^{3}$ Department of Mechanical, Konya Technical University, Konya,Turkey (ORCID: 0000-0003-4491-0228) \\ ${ }^{4}$ Department of Visual, Auditory, Techniques and Media productions , Konya Technical University, Konya,Turkey (ORCID: 0000-0003-1553-581X) \\ *(hterzioglu@ktun.edu.tr) \\ (Bu yayın International Congress on Human-Computer Interaction,Optimization and Robotic Application kongresinde sözlü \\ olarak sunulmuştur.)
}

(First received 1 August 2019 and in final form 25 October 2019)

(DOI: 10.31590/ejosat.638378)

ATIF/REFERENCE: Terzioğlu, H., Ağaçayak, A. C., Yalçın, G. \& Neşeli, S. (2019). Asenkron Motorun Çalışma Parametrelerinin SCADA ile İzlenmesinin Tasarımı. European Journal of Science and Technology, (Special Issue), 418-427.

\section{Özet}

Asenkron motorlar; doğrudan bir fazlı ya da üç fazlı alternatif akım şebekesinden beslenebilmesi， dayanıklı， bakım gerektirmeyen yapısı ve düşük maliyetleri nedeniyle, hem sanayide hem de ev aletlerinde en çok kullanılan motor türü haline gelmiştir. Asenkron makinelerin, senkron makinelerinden en büyük farkı dönme hızının sabit olmayışıdır. Motor olarak çalışan bir asenkron motorda bu hız, senkron hızdan küçüktür. Makine bu özelliğinden dolayı, asenkron makine adını almıştır. Dünyada üretilen enerjinin \%70 civarındaki kısmının asenkron motorlarda tüketiliyor olması bu motorların kullanım sıklığını ve önemini göstermektedir. Yapılarının basit, ekonomik ve sağlam olmaları, bakım gerektirmemeleri ve her türlü ortam koşullarında çalışabilmeleri gibi üstün özellikleri nedeniyle asenkron motorlar, endüstride yaygın olarak kullanılmaktadır. Yaygın olarak kullanılan asenkron motorların kontrolünde çeşitli sürme teknikleri kullanılmaktadır. Bu sürme tekniklerine göre asenkron motorların matematiksel modellemesinin gerçekleştirilmesi de önemli bir çalışma konusudur. Asenkron motorlarının dinamik performanslarının incelenmesi ve matematiksel modellerinin çıkartılabilmesi için parametrelerinin doğru olarak hesaplanması gerekmektedir. Bu çalışmada asenkron motorların en büyük sorunlarından birisi olan parametrelerinin doğru olarak belirlenmesi amaçlanmıştır. Bilgisayar ve mikroişlemci teknolojisinin gelişmesine bağlı olarak asenkron motor parametrelerinin tespiti hem kolaylaşmış hem de daha önem kazanmıştır.

Bu çalışmayla yaygın olarak kullanılan asenkron motorların çalışma parametreleri olan akım, gerilim, cos $\varphi$, tork, güç değerlerinin operatör panelinde okunmasının sağlanacağı bir SCADA sisteminin tasarımı gerçekleştirilmiştir. Bu sistemde PLC, HMI ve hız kontrol cihazı haberleştirilerek asenkron motorun çalışma parametreleri HMI ekranında görüntülenebilecektir. Ekranda görüntülenen veriler kullanılarak asenkron motorun istenilen değerlerine hesaplama yöntemleri kullanılarak ulaşılabilecektir. SCADA programında asenkron motor parametrelerinin en doğru ve en hızlı şekilde hesaplanacağı bir algoritma tasarlanacaktır. Parametre değerlerinin doğru olarak hesaplanması motorun dinamik etkilerinin belirlenmesinde ve sürme devrelerinin tasarlanmasında büyük bir gelişme sağlayacaktır.

\section{Design of Monitoring of Induction Motor Operating Parameters with SCADA}

Abstract 
Induction motors; Due to its durability, maintenance-free structure and low cost, it can be supplied directly from a single phase or three phase alternating current network. The biggest difference of asynchronous machines from synchronous machines is that the rotational speed is not constant. In an asynchronous motor operating as a motor, this speed is smaller than the synchronous speed. The machine is named asynchronous machine because of this feature. The fact that around $70 \%$ of the energy produced in the world is consumed in asynchronous motors shows the frequency and importance of these motors. Asynchronous motors are widely used in industry due to their simple, economical and robust structure, maintenance-free and superior operating conditions. Various control techniques are used for the control of commonly used asynchronous motors. Mathematical modeling of asynchronous motors according to these driving techniques is also an important subject of study. In order to investigate the dynamic performances of induction motors and to obtain mathematical models, it is necessary to calculate the parameters correctly. In this study, one of the biggest problems of induction motors is aimed to determine the parameters correctly. Due to the development of computer and microprocessor technology, determination of asynchronous motor parameters has become easier and more important.

In this study, the design of a SCADA system, which will enable reading of current, voltage, $\cos \varphi$, torque, power values which are the operating parameters of commonly used asynchronous motors, has been realized. In this system, PLC, HMI and speed controller will be communicated and the operation parameters of the induction motor will be displayed on the HMI screen. Using the data displayed on the screen, the desired values of the asynchronous motor can be reached using calculation methods. In the SCADA program, an algorithm will be designed in which the asynchronous motor parameters will be calculated in the most accurate and fastest way. Accurate calculation of parameter values will provide a great improvement in determining the dynamic effects of the motor and designing the driving circuits.

Keywords: Induction motor, Speed control, PLC, HMI, SCADA.

\section{Giriş}

Endüstriyel uygulamalarda yaygın olarak kullanılan asenkron motorların yapılarının basit ve sağlam olmaları, bakıma az ihtiyaç duymaları, maliyetlerinin düşük olması ve verimlerinin yüksek olması sebebiyle endüstriyel uygulamalarda tercih edilen motorlardandır. Yaygın olarak kullanılan asenkron motorların kontrolünde çeşitli sürme teknikleri kullanılmaktadır. Kullanılan bu sürme tekniklerine göre asenkron motorların matematiksel modellemesinin gerçekleştirilmesi de önemli bir çalışma konusudur. Bu çalışmada asenkron motorların en büyük sorunlarından birisi olan parametrelerinin doğru olarak belirlenmesi amaçlanmıştır. Bilgisayar ve mikroişlemci teknolojisinin gelişmesine bağlı olarak asenkron motor parametrelerinin tespiti hem kolaylaşmış hem de daha önem kazanmıştır.

Asenkron motorlarının dinamik performanslarının incelenmesi ve matematiksel modellerinin çıkartılabilmesi için parametrelerinin doğru olarak hesaplanması gerekmektedir. Teknolojik gelişmelere bağlı olarak gelişen yapay zeka teknolojilerinden YSA, Bulanık Mantık gibi önceden seziş özelliklerine sahip Genetik Algoritma, Diferansiyel Genetik Algoritma, Parçalı Sürü Optimizasyonu gibi optimizasyon amaçlı kullanılan yöntemler günümüzde yaygınlaşmıştır. Bu algoritmaların başarısı asenkron motorun değişen parametrelerinin modele doğru yansitılmasıyla doğru orantılı olarak giderek artacaktır.

Son zamanlarda, sensörsüz endüksiyonlu motor sürücülerinin performansını artırmak için birçok çalışma yapılmıştır. Bununla birlikte, parametre değişimleri ve düşük hızlı işlemler, sensörsüz tahriklerin doğruluğunu ve dengesini etkileyen en kritik hususlardır. Cherif ve Miloud yaptıkları çalışmada sensör hızı ihtiyacını aşan bir hız tahmin algoritmasının ilk elden ve ikincisi sistemde mevcut belirsizlikleri telafi eden güçlü değişsen yapı kontrol yasalarından oluşan sensörsüz bir vektör kontrol şeması sunmaktadır. Endüksiyon motorunun hız sensörsüz kontrolü için rotor hızı ile rotor ve stator direnci arasındaki eşzamanlı tahmini önermektedirler (Cherifi \& Miloud, 2019). Atkinso ve ark. Kalman filtresinin, ölçülmemiş durumların optimal bir tahminini üretmek için tesis modelinden gelen bilgileri çıkış ölçümleriyle birleştirerek endüksiyon motorundaki rotor akımlarının tahmini için nasıl kullanılabileceğini göstermiştir (Atkinson, Acarnley, \& Finch, 1991). Aminu yüksüz ve kilitli rotor testlerine ihtiyaç duyulmaksızın IM parametrelerini tahmin etmek için bir yöntem sunar. Yöntem, Yapay Arı Kolonisi (ABC) optimizasyonu adı verilen nispeten yeni bir sürü tabanlı algoritmayı kullanarak optimizasyon yaklaşımına dayanır. Elde edilen deneysel sonuçlara dayanarak, ABC algoritması hem paralel hem de seri eşdeğer devreler için makine parametrelerini kabul edilebilir doğruluk seviyesinde izleyebildi. Bununla birlikte, sonuçlar seri eşdeğer devre uygulamasının yüzde hata ve tekrarlanabilirlik açısından daha fazla doğruluk sağladığını göstermektedir(Aminu, 2019). Gastli önerdiği yöntemde, tek fazlı test sonuçlarını asenkron motorun eşdeğer devre parametrelerini hesaplamak için temel bir test olarak kullanır. Önerilen yöntemi kullanmanın avantajları üç yönlüdür: i) testler sürüş sistemine başlamadan önce herhangi bir zamanda yapılabilir, ii) motorun sürüş sistemi içine mekanik montajı ile ilgili herhangi bir kısıtlama yoktur ve iii) ölçümler arasında motor parametreleri ve motor bağlantı kablolarının empedansı bulunur(Gastli, 1999). Jabbour ve Mademlis ise endüksiyon motorlu (IM) bir sürücüde yüksek performanslı hız kontrolü sağlamak için ayrık zamanlı model öngörülü kontrolörün parametrelerini çevrimiçi ve otomatik olarak tahmin edip ince ayar yapabilen yeni bir yöntem sunar. Önerilen kontrol sistemi, model referans adaptif yöntemini bulanık mantık tekniği ile birleştirir ve herhangi bir insan müdahalesi veya motor tahrik parametrelerinin bilgisi gerektirmeden çalışması başlatılabilir. Önerilen otoadaptif ayrık zaman modeli kestirimsel kontrol ADMPC sisteminin etkinliğini doğrulamak ve motor sürücünün yüksek performansını göstermek için seçici simülasyon ve deneysel sonuçlar sunulmuştur (Jabbour \& Mademlis, 2018). Yamamoto ve ark. endüksiyon motorlarının (IM) çift kafesli rotor eşdeğer devre parametrelerini belirlemek için basit bir yöntem sunar. Çift kafesli rotor eşdeğer devre parametrelerini hesaplamak için yeni bir formül önerilmiştir. Önerilen yöntem, kapalı bir slot rotorunun manyetik doyma etkisini hesaba katar ve sadece çift kafesli değil, aynı zamanda tek kafesli IM'ler için de geçerlidir. Tüm eşdeğer devre parametreleri sadece klasik yüksüz ve kilitli rotor testleri kullanılarak belirlenebilir. Bu nedenle, önerilen yöntem IM'ler için standart bir test yöntemi olarak kullanılmaya uygun olduğu belirtmektedirler 
(Yamamoto, Hirahara, Tanaka, \& Ara, 2018). Cui ve ark. çalışmalarında ZIP yük ve endüksiyon motorlu (IM) kompozit yük modellemesi (CLM) için derin öğrenme temelli, zamana göre değişen parameter tanımlama (TVPI) modeli geliştirmektedir. Çok geniş modal uzun süreli kısa süreli hafıza (M-LSTM) derin öğrenme yöntemi, sistem çapında ölçümler göz önüne alındığında, CLM'nin her zaman değişen parametrelerini tahmin etmek için kullanılır. Zamana göre değişen yük parametrelerini doğru bir şekilde tahmin etmek için giriş verilerinin farklı modlarından faydalanan çok modlu bir yapı içerir. 23 ve 68 bus sistemlerindeki sayısal simülasyonlar, önerilen M-LSTM yönteminin etkinliğini ve sağlamlığını doğrular. Ayrıca, giriş değişkenleri olarak parametrelerin ve ölçümlerin optimal gecikme değerleri de çözülür (Cui et al., 2019). Dolinar ve ark. üç fazlı bir kafes endüksiyon makinesinin iki eksenli bir modelinin parametrelerini belirlemek için sonlu elemanlar yönteminin kullanımını sunmaktadır. Önerilen yöntem, doymuş ve doymamış durumda hem rotor hem de stator kaçağı indüktanslarının gerekli şekilde ayrılmasını ve mıknatıslama akımının bir fonksiyonu olarak mıknatıslanma reaktansının hesaplanmasını sağlar. Ayrıca, çok verimli ve basit bir rotor direnci hesaplaması sağlanır. Makinenin tüm çalışma bölgesinde tamamen bilinen bir dizi parametre ile endüksiyon motorunun tarif edilen modeli, endüksiyon motorlarının gelişmiş kontrol sentezinde verimli bir şekilde kullanılabilir (Dolinar, De Weerdt, Belmans, \& Freeman, 1997). Shaw ve ark. başlangıç geçici verileri kullanılarak bir endüksiyon motorunun toplu model parametrelerini tahmin etmek için üç yöntem açıklanmaktadır. Tanımlama prosedürü için stator akımlarının ve gerilimlerinin ölçümü gereklidir, ancak motor milinden ölçüm gerekmez. Sunulan ilk yöntem, sınırlı geçici geçerliliği olan basit modelleri uygular ve model hata yanlılığını sıfıra ekleyerek parametre tahminleri alır. Bu yöntem, belirli bir hata kriterini en aza indirmez ve geleneksel bir yinelemeli maksimum olabilirlik veya en küçük kareler tahmincisi için iyi bir ilk tahmin bulma aracı olarak sunulur. Sunulan ikinci yöntem, Levenburg-Marquardt yinelemesini kullanarak endüksiyon motor modelindeki en küçük kareler anlamında denklem hatalarını en aza indirir. Üçüncü tanımlama yöntemi, bazı patolojik kayıp fonksiyonlarının gözlenen özellikleri tarafından motive edilen Levenburg-Marquardt yönteminin bir devamıdır. Üçüncü yöntem, gözlemlerdeki hataları en küçük kareler anlamında en aza indirger ve bu nedenle, uygun normallik koşulları altında bir maksimum olabilirlik tahmincisidir (Shaw \& Leeb, 1999). Nangsue ve ark. genetik algoritmaların ve genetik programlamanın temel kavramlarını sunmuştur ve endüksiyon makinelerinde bir parametre belirleme probleminin bu teknikleri kullanarak çözümüne izin vermek için nasıl formüle edilebileceğini göstermiştir. Üç farklı eşdeğer devre kullanan üç farklı motor büyüklüğü dikkate alınmıştır. Bu motor parametreleri, motor koruma için tekrar kapama geçici geçişlerinin hesaplanması gibi sistem düzeyinde çalışmalarda kullanılabilir (Nangsue, Pillay, \& Conry, 1999). Moreira ve ark. kablo ve motor sargılarının frekans tepkileri deneysel olarak elde edilmiş ve deneysel sonuçlara uyacak şekilde uygun modeller geliştirilmiştir. Kabloyu modellemek için hattın kayıplı bir gösterimini içeren birkaç parçalanmış bölüm kullanılır. Kablo ve endüksiyon motoru modelleri, Matlab gibi bir hesaplama aracı kullanılarak uygulanabilir ve böylece aşırı voltaj olaylarını analiz etmek için uygun bir yöntem sağlar. Simülasyon ve deneysel sonuçlar, geliştirilen simülasyon modellerinin uygunluğunu gösteren tipik bir $3 \mathrm{hp}$ endüksiyon motoru için sunulmuştur. Tüm parametrelerin sürücü çalışması sırasında kaçınılmaz olarak değiştiğinden, çevrimiçi bir parametre tahmincisi ekleyerek sürücünün performansını iyileştirmek genellikle istenir. Böyle bir durum, son yirmi yılda çok sayıda çevrimdışı parametre tanımlamanın ve çevrimiçi parametre tahmin yönteminin geliştirilmesine yol açmıştır (Moreira, Lipo, Venkataramanan, \& Bernet, 2002). Toliyat ve ark. mevcut yöntemleri gözden geçirmek ve konuyla ilgili kapsamlı bir kaynakça sağlamak için girişimde bulunmuştur (Toliyat, Levi, \& Raina, 2003). Unem ve Vadstrup iki endüksiyon motorunun parametre tanımlamasına diferansiyel evrim algoritmasını uygulamıştır. Sunulan deneyler diferansiyel evrim kullanmaktadır ve iki motor tanımlama problemi üzerinde sekiz stokastik arama algoritmasının karşılaştırılmasının bir takip çalışmasıdır. Sonuç olarak, diferansiyel evrim algoritması her iki problem için bilinen en yüksek algoritmaları geride bıraktı (Ursem \& Vadstrup, 2003). Pedra ve Córcoles pahalı test veya parametre tahminleri yapmadan endüksiyon makinesi çift kafesli modeller için üretici bilgisinin simülasyon bilgisine dönüştürülmesi için basit bir yöntem önermektedir (Pedra \& Corcoles, 2004). Matsuo ve Lipo endüksiyon motorunun rotor direncinin tam değerini belirlemek için bir çevrimiçi teknik tarif etmişlerdir. Rotor direncinin tanımlanması, negatif dizilim akımının enjekte edilmesi, negatif dizilim voltajının tespit edilmesi ve elde edilen bilgiden rotor direncinin değerinin hesaplanması ile elde edilir. Bu tekniğin matematiksel ifadeleri türetilmiş ve geçerliliği analog bilgisayar simülasyonu ile gösterilmiştir (Matsuo \& Lipo, 1985). Pedra, lineer olmayan bir denklem sisteminin yeni bir sayısal yöntemle (modifiye Newton yöntemi) çözümüne katkıda bulunur. EMTP tipi simülasyon programlarında (ATP, EMTP96, EMTDC) kullanılan endüksiyon motor parametresi belirleme yönteminin yanlış olduğu tartışılmıştır. Çalışmada, üretici verilerinden çift kafes parametrelerini bulmak için çok sağlam bir yöntem sunmuştur. Önerilen yöntem, Newton yönteminin bir modifikasyonuna dayanmaktadır. Algoritma, verilerin doğru olmadığı, çözülemeyen veriler olarak adlandırılan durumların tanımlanmasına izin verir. Çözülemeyen verilerin vakaları incelenmiştir (Pedra, 2008). Haque NEMA tasarım A ve B tip endüksiyon motorlarının üretici verilerini, kaymaya bağlı rotor parametreleriyle eşdeğer bir devre modeline dönüştürmek için basit bir yöntem önermektedir. Parametreleri belirlemek için kullanılan doğrusal olmayan denklemler seti $\mathrm{F}(\mathrm{x})=0$ şeklinde türetilir ve en küçük kareler tabanlı bir algoritma kullanarak çözüldü. Doğru sonuçları elde etmek için maksimum tork ve karşılık gelen kayma denklemleri de bu yazıda gözden geçirilmiştir (Haque, 2008). Mirafzal ve arkadaşları önceden önerdikleri düşük ila yüksek frekanslı asenkron motor modelinin parametrelerini belirlemek için sistematik bir prosedür sunmuşlardır. Asenkron motorun frekans karakteristiklerini belirlemek için sırasıyla uygulama ve tasarım aşamalarında yararlı olan test bazlı bir yöntem ve analitik bir yaklaşım sunulmaktadır. Araştırmanın bulguları, bu çalışmada sunulan sonuçlarla deneysel olarak doğrulanmıştır (Mirafzal, Skibinski, \& Tallam, 2009). Boglietti ve ark. endüksiyon motoru eşdeğer devre boyuna parametrelerinin (faz dirençleri ve kaçak indüktanslar) hesaplanması için yöntemler sunmuşlardır ve yarık eğriltme etkileri dikkate alınarak derinlemesine analiz edilmiştir. Önerilen yöntemler ve algoritmalar, genellikle elektromanyetik bir tasarımdan sonra mevcut olan geometrik ve elektriksel verileri gerektirir. İndüksiyon motor eşdeğer devre parametresi hesaplamasıyla ilgilenen tasarımcılara yardımcı olmak için, tam bir teorik analiz ve sayısal bir kod geliştirmek için adım adım algoritmalar çalışmalarına dahil etmişlerdir. İnvertörle beslenen endüksiyon motorunun demir kaybının hızlı ve doğru bir şekilde tahmin edilmesi, demir kaybını en aza indirgemek için uygun yöntemler önermek açısından büyük önem taşımaktadır (Boglietti, Cavagnino, \& Lazzari, 2010). Zhang ve ark. hızlı ve doğru bir analitik invertör beslemeli endüksiyon makinesi demir kaybı hesaplama modeli önermişlerdir. Önerilen model, çıkış gerilimi harmoniklerinin invertörden, parça parça değişken katsayılar yöntemine dayanarak motorun demir kaybı üzerindeki etkisini dikkate almaktadır. Önerilen modelin geçerliliği, hesaplanan çekirdek kayıp değerleri $5.5 \mathrm{~kW}$ ve $55 \mathrm{~kW}$ invertör beslemeli endüksiyon motorlarının farklı hız ve yük e-ISSN: 2148-2683 
koşullarında ölçülen değerleri ile karşılaştırılarak doğrulanır. Klasik demir kaybı modeli ve parça parça değişken katsayılı demir ile karşılaştırılır. Sonlu elemanlar yöntemine dayalı kayıp modeli, önerilen model, hesaplama yükünü istenen doğrulukla önemli ölçüde azaltabileceği belirtilmektedir (Zhang, Liu, Zhao, \& Wu, 2019). Cao ve ark. şehir içi demiryolu taşımacılığı için LFSPM'ler FEM kullanılarak benzer bir LIM uygulama ile tasarlanmış, optimize edilmiş ve karşılaştırılmıştır. LIM'lerin FEM modeli referanslara göre oluşturulur ve referanslarla karşılaştırılarak doğrulanır. Daha sonra, demiryolu taşımacılığı için LFSPM'lerin tasarlanması için sayısız ilkeler belirlenmiştir. Prensipler temelinde, farklı kutup numaralarına sahip üç LFSPM hazırlanır ve 4ABC tipi LFSPM seçilir ve optimize edilir. LFSPM'lerin ve LIM'in itme kuvveti, itme kuvveti dalgalanmas1, normal kuvvet, normal kuvvet dalgalanmas1, verimlilik ve güç faktörü özetlenir ve karşılaştırılır. Bu nedenle, LFSPM'ler LIM'den daha yüksek bir itme kuvveti, verim ve güç faktörüne sahiptir. Dahası, bu motorlar daha kolay 1sı yayılımına, daha yüksek hıza ve LIM'den daha az kendi kendine endüktansa sahiptir. Bununla birlikte, LFSPM'ler oldukça büyük normal kuvvetlerine ve kuvvet dalgalanmalarına maruz kalırlar. LFSPM'lerin ekonomik ve yük performansını daha iyi değerlendirmek için, Guangzhou metro hattı 4 şartı altında incelenmiştir. LFSPM'nin iyi bir yük performansına sahip olduğunu ve enerji tasarrufu kabiliyetinin, malzemenin maliyetinin dezavantajını telafi edecek kadar kayda değer olduğunu göstermektedir. FEM sonuçlarını doğrulamak için küçük ölçekli bir LFSPM prototipi oluşturularak denemişlerdir. Deneysel sonuçlar FEM sonucuna karşılık gelir, böylece LFSPM'lerin performansını araştırmak için FEM kullanmanın fizibilitesini desteklemiştir (Cao, Lu, Jiang, \& Cheng, 2019).

Bu çalışmada yaygın olarak kullanılan asenkron motorların çalışma parametreleri olan akım, gerilim, cos $\varphi$, tork, güç değerlerinin operatör panelinde okunmasının sağlanacağı bir SCADA sisteminin tasarımı gerçekleştirilmiştir. Bu sistemde PLC, HMI ve hız kontrol cihazı haberleştirilerek asenkron motorun çalışma parametreleri HMI ekranında görüntülenebilecektir. Ekranda görüntülenen veriler kullanılarak asenkron motorun istenilen değerlerine hesaplama yöntemleri kullanılarak ulaşılabilecektir. SCADA programında asenkron motor parametrelerinin en doğru ve en hızlı şekilde hesaplanacağı bir algoritma tasarlanacaktır. Parametre değerlerinin doğru olarak hesaplanması motorun dinamik etkilerinin belirlenmesinde ve sürme devrelerinin tasarlanmasında büyük bir gelişme sağlayacaktır. Ayrıca güç elektroniğindeki ve mikro-elektronikteki gelişmeler asenkron makinelerin hız kontrolünü kolaylaştırdığından kullanım alanı daha da yaygınlaşmıştır. Bu çalışmada bütün bu gelişmelerde göz önüne alınarak asenkron motorların hız kontrolüne değişik bir açıdan yaklaşılacak ve motor parametrelerine göre değişen bir sistem tasarlanabilmesi için bir ön çalışma oluşturacaktır.

\section{Materyal ve Metod}

Asenkron motorun SCADA ile kontrol edilmesini ve çalışma performans parametrelerinin elde edilebilmesi için Şekil 1'deki blok şema önerilmiştir.

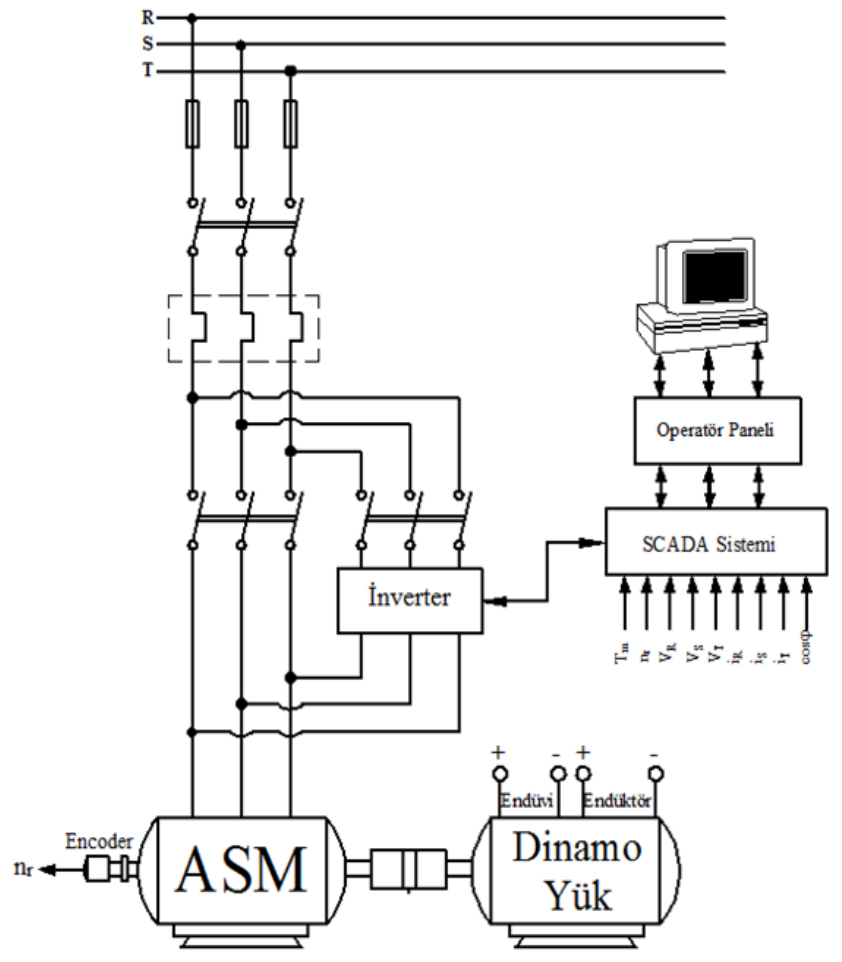

Şekil 1. Deney Düzeneği Blok ŞemasıServomotor çalışma sisteminin blok diyagramı

Şekil 1'de verilen blok şemaya ait pano tasarımı Şekil 2'deki gibi temsili pano haline dönüştürülecektir. Panonun kapağın üst tarafina KTP700 Basic PN, 7" HMI, PROFINET arayüzü, 800 x 480 çözünürlüklüğ operator paneli yerleştirlecektir. Operatör panelin altına bir güç analizörü yerleştirilmesi düşünülmektedir. 

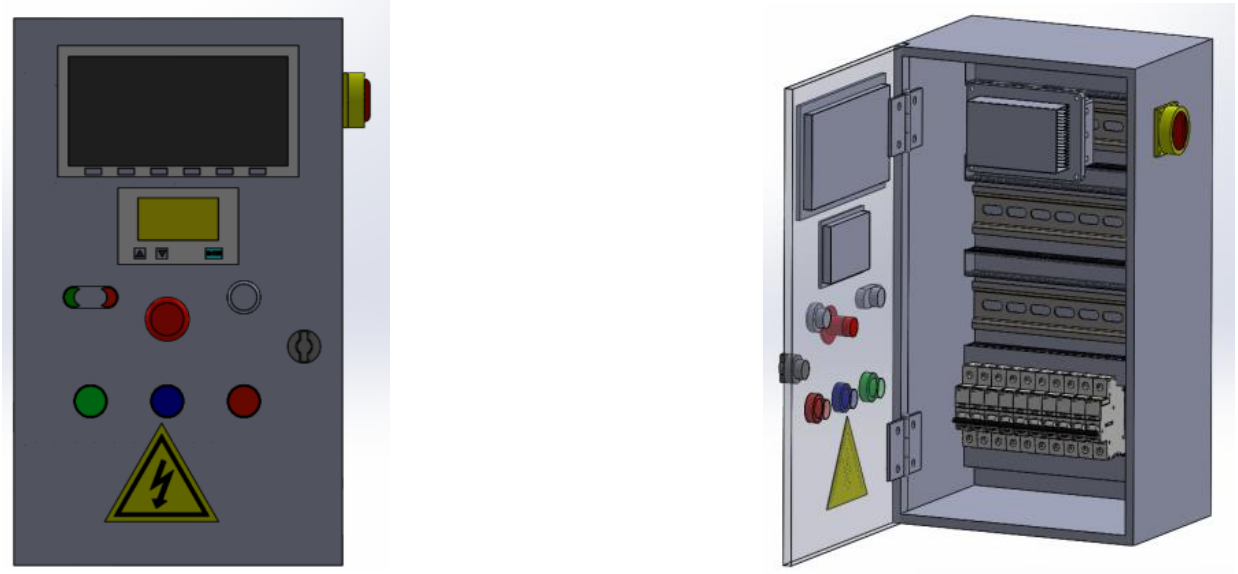

Şekil 2. Asenkron Motorun Kontro Ünitesi

Pano kapağının alt tarafınada star/stop butonları acil stop butonu ve enerji lambaları konumlandırılmıştır. Panonun iç kısmında en üste siemens S7 1200 PLC, altına hız kontrol cihazı SINAMICS G120 Power Module PM240-2 ile SIMATIC S7-1200, Analog input, SB 1231RTD, 1 AI RTD, PT100 ve PT1000 sıcaklık ölçüm modülü konumlandırılacaktır.

Asenkron motorun kontrol ünitesi tamamlandıktan sonar motorun yüklenmesini, motorun devrinin ölçülmesini sağlayacak Şekil 3'deki bağlantı gerçekleştirilecektir.

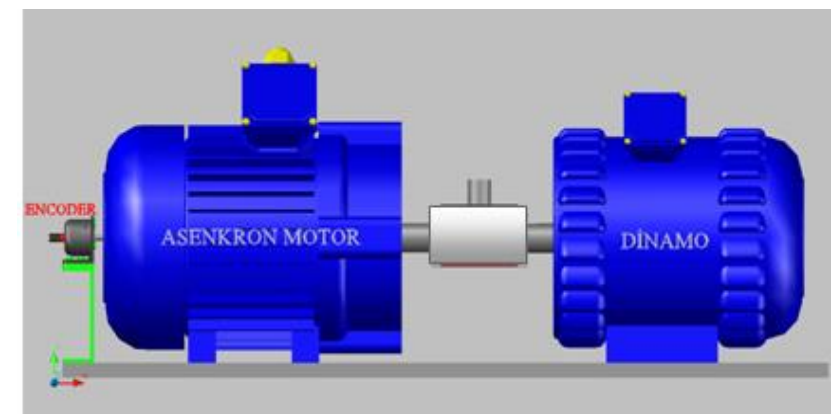

Şekil 3. Asenkron Motorun Doğru Akım Motoru ile Akuple Bağlantısı

Çalışmada kullanılması planlanan malzemeler aşağıdaki gibi sıralanmıştır;

\subsection{Hız Kontrol Cihazı}

Hız control cihazı olarak Siemens marka hız kontrol cihazı SINAMICS Power Module PM240-2 tercih edilniştir. Şekil 4'de kullanılan hzı control cihazının resmi görülmektedir.

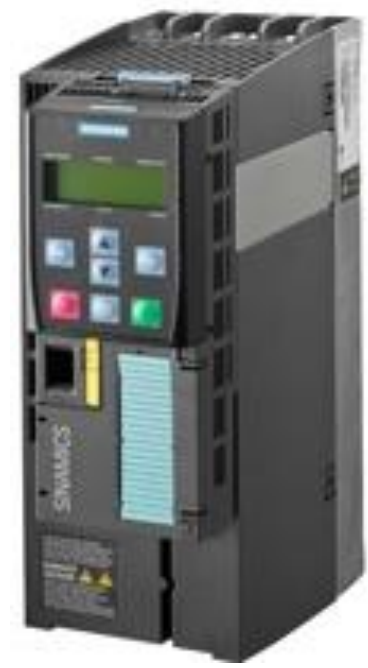

Şekil 4. Modüler AC Motor Hız Kontrol Ünitesi (İnt.Kyn.1)

SINAMICS G120 serisi hız kontrol cihazları, temel olarak 2 ana kısımdan oluşmaktadır 
- $\quad$ Kontrol birimi (CU)

- $\quad$ Güç modülü $(\mathrm{PM})$

İstenilen kontrol birimi, güç modülünün üzerine kolayca takılabilir. Güç modülü, 0.37 kW'dan 250 kW'a (VT) kadar güç aralığında bulunmaktadır.

SIZER ve STARTER gibi yazılımlarla programlama yapılabildiği gibi, temel operatör paneli (BOP) kullanılarak da cihaza kumanda etmek mümkündür. Ayrıca MMC kart yardımı ile mevcut veriler başka bir sürücüye kolayca taşınabilir.

Sinamics G120 PM240 güç modülü, dahili frenleme ünitesinin üst sınırını 132 kW'a kadar taşırken Rejeneratif özelliğe sahip PM250 güç modülü, frenleme esnasında ortaya çıkan enerjiyi frenleme direncine ihtiyaç duymadan tekrardan şebekeye geri verebilecek giriş güç katı teknolojisine sahiptir (İnt.Kyn.1).

\subsection{CPU Modülü}

Siemens marka hız kontrol cihazının CPU modülü - Siemens CU250S-2 PN tercih edilniştir. RS 485/USS/Modbu s RTU haberleşme kullanılmaktadır. 11 dijital girişe ve 3 dijital çıkışa sahiptir. Aynı zamanda 2 analog girişi ve 2 de analog çıkışı vardır.

\subsection{Programlanabilir Lojik Kontroller (PLC)}

Programlanabilir Lojik Kontroller olarak Siemens S71200 serisi tercih edilmiştir. Kompakt yapısı ve güçlü işlem yapabilme yeteneğiyle kullanışlı bir PLC'dir. Farklı CPU çeşitleriyle piyasaya sürülen S7-1200, kullanıcınin ihtiyaçlarını karşılayacak şekilde tasarlanmıştır. CPU-1211C, CPU-1212C ve CPU-1214C olmak üzere 3 farklı modeli bulunmaktadır. Her modelin Input/Output (Giriş/Çıkış) sayısı, RAM miktarı, işlemci hızı gibi özellikleri birbirinden farklıdır (İnt.Kyn.2).

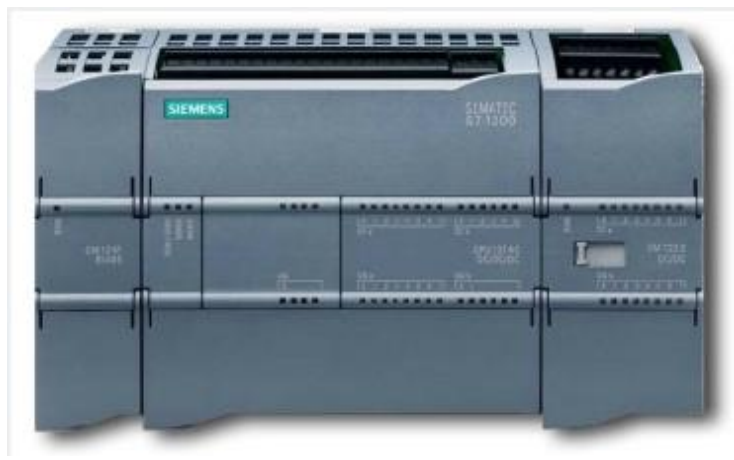

Şekil 5. Modüler AC Motor Hız Kontrol Ünitesi (İnt.Kyn.2)

\subsection{Operatör Paneli (HMI)}

KTP700 Basic PN, 7" HMI, PROFINET arayüzü, 800 x 480 çözünürlüklüdür. Temel otomasyon uygulamaları için yüksek çözünürlüklü, TFT 64000 renk dokunmatik geniş ekrana sahiptir. Alarm, trend, reçete fonksiyonları (geliştirilmiş reçete objesi). Yenilenmiş obje, kontrol objeleri, grafikler sayesinde yenilikçi tasarımda modern kullanıcı arayüze sahiptir. 800 tag projelendirilebilir. Tek bir haberleşme arayüzü mevcuttur. USB arayüzü sayesinde mouse, keyboard desteği ve USB stick'e arşivleme özelliği mevcuttur. STEP7 Basic V13 veya WinCC V13 Basic sürümlerinden itibaren projelendirilebilir (İnt.Kyn.3).

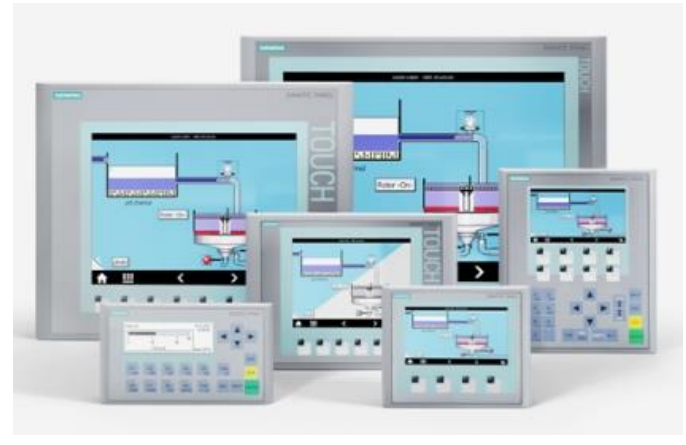

Şekil 6. KTP700 Basic PN, 7" HMI Operatör Panel (İnt.Kyn.3)

\subsection{Operatör Paneli (HMI)}

Sicaklık Termokupl veri okuma modülü olarak SIMATIC S7-1200, Analog input, SB 1231RTD, 1 AI RTD, PT100 ve PT1000 modül tercih edilmiştir. Çalışma voltajı 24V DC dir. 


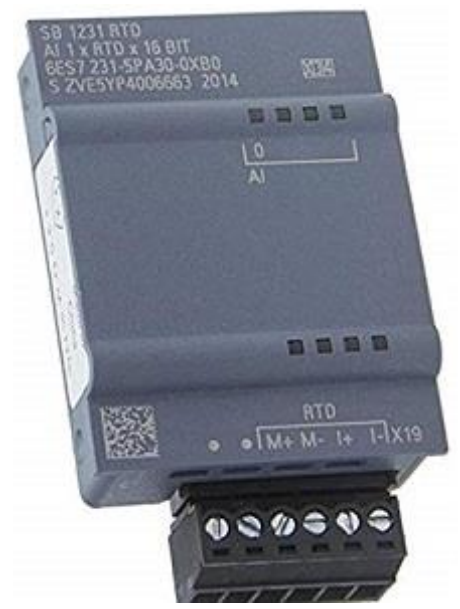

Şekil 7. KTP700 Basic PN, 7" HMI Operatör Panel (İnt.Kyn.4)

\subsection{Sıcaklık Sensörü}

Elektronik 1sı duyargalarından çok fazla tercih edilen devre elemanlarından biri Pt100 lerdir. Özü itibarı ile sıcaklığa bağlı olarak direnç değerinin değişmesi ile diğer başka bir cihazla sıcaklık değeri anlaşılan bi aparattır. Hedef malzemenin ısısını ölçmek için bu dirençler daha mukavemetli başka bir kutunun içine yerleştirilerek sağlıklı ölçüm yapılabilmektedir. PT100 iletken bir telin direnç değerinin sıcaklıkla değişmesinden istifade edilerek oluşturulan bir sıcaklık algılayıcısıdır. Sarımlı direnç sıcaklığı hissedilmek istenilen bölgeye daldırılır, ve hedeften sabit akım geçirilir. Sıcaklığın değişimi ile sarımlı direncin direnç değeri değişeceğinden ve fark akımı sabit akımla arasından. voltaj alınır. Rezistans termometreler'de sıcaklık değişim faktörü olarak á tanımlanır. Ve 0 santigrat derecede değeri 100ohm dur (İnt.Kyn.5).

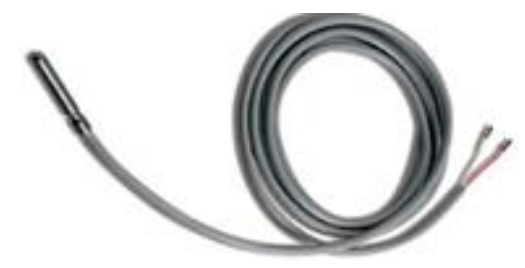

Şekil 8. PT100 Sıcaklık Sensörü (İnt.Kyn.5)

\subsection{Encoder Line Drive}

Servo sürücüleri, diğerlerinden ayıran en büyük özellik konumunun kontrol edilebilmesidir. Eğer konum kontrol edilebiliyorsa motor milinin (veya bağlı olan sistemin bulunduğu noktanın ) konum bilgisinin de bilinmesi gerekir. Servo sürücüde konum bilgisinin geri dönüşü için Encoder veya Resolver elemanları kullanılır.

Encoder bağlı olduğu motor milinin hareketine karşılık sinyal üreten sayısal (dijital) bir elektrik (pulse) sinyali üreten elektromekanik bir cihazdır. Ayrıca bağlanan milin mevcut konumlarını izlemek ve geri bildirim sağlayan bir algılama cihazıdır. Kodlayıcıkonum, sayı, hız veya yönü belirlemek için kullanılabilen bir geribildirim sinyali gönderir. Genellikle servo motor, robot, hareketli kamera, cnc tezgahları, otomasyon gibi bir çok kullanım alanları vardır. Doğrusal ve döner olmak üzere ikiye ayrılır.

Encoderler, sinyal oluşturmak için farklı teknolojiler kullanır. Bunlar manyetik, mekanik, dirençli ve optik dir. Ençok kullanılan ise optik olanıdır. Optik algılamada, kodlayıcı ışık kesintisine dayalı olarak geri bildirim sağlar. Encoder Şaftının, Bağlantı Şekillerine göre; Delik Milli Tip (Hollow Shaft Encoder) ve Milli Tip (Shaft Encoder) iki çeşittir.Sinyal algılama da manyetik ve optik algılamalı olarak iki çeşittir.Pozisyon konum belirlemede Mutlak (Absolute Encoder) ve Artımsal (Incremental Encoder) iki çeşittir.

Mutlak encoder: encodera güç verildiği anda dönen mile göre dijital bit dizileri şeklinde birbirine benzemeyen çıkışlar vererek konumu belirler. enerji kesilse dahi en sonki konumunda kalır.Ve tekrar enerjilendiğinde kaldığı konumdan işlemine devam eder.

Artımsal encoder: Dönen mil için sürekli kare sinyal üreterek bulunduğu konumu bilgilendirmede ve sayma işlemlerinde kullanılır. Bu tip encoderlar mutlak encoderlardan fark1 enerjilendikleri andan itibaren bulunduğu konumu 0 olarak kabul eder; ve bu değerin üstüne işlem yapar. $\mathrm{Bu}$ tip encoderler endüstriyel robotlar, Cnc Tezgahlarda, Antenler, Medikal cihazlar, Paketleme makinaları Deri işleme makinaları, şişeleme makinalarında vb alanlarda kullanılır.

Encoder Seçiminde Nelere Dikkat Edmeliyiz 
*Puls Sayısı: Encoderin her dönüşte üretilen puls sayısı öğrenilmeli

*Besleme Gerilimi: 5VDC., 5-30VDC, 11-24VDC.vb.

*Çıkış Gerilimi: besleme geriliminden farklı çıkış gerilimi veren encoderler vardır. Bu yüzden *kullancağımız cihaza göre çıkış gerilimi önemlidir.

\section{*Referans Çıkışının Genliği:}

*Fiziksel Özellikler Gövde Çapı / Gövde Uzunluğu:

*Malzemesi: ABS, alüminyum, çelik vb. tamamen çalışma ortam koşullarına bağlı olarak.

*Milli mi? / Delik Milli mi?

*Bağlantılar(Kablolu / Soketli):

*Soket / Kablo Çıkış Yönü (Eksenel / Yandan Çıkışl1):

*Soket Tipi / Kablo Damar Sayısı ve Uzunluğu:

*Koruma Sinıfi

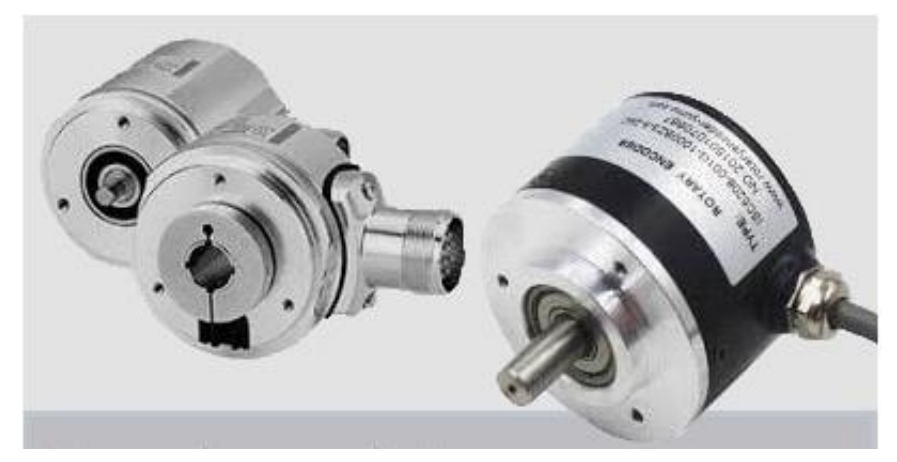

Şekil 9. Encoder (İnt.Kyn.6)

\section{Araştırma Sonuçları ve Tartışma}

$\mathrm{Bu}$ çalışma ile asenkron motorun eşdeğer devre parametre değerlerinin gerçek zamanlı olarak doğru hesaplanacağı bir SCADA yazılımı gerçekleştirilmesi, parametre değişimlerinin asenkron motorun performansı üzerindeki etkilerinin belirlenmesi ile çalışmanın başarılı olduğu anlamına gelecektir. Çalışmada, tam başarı için, kullanılan bütün veriler ile ilişkili bir sistem oluşturulması hedeflenmektedir. Çalışmada elde edilmesi planlanan hedeflerin önem sırası ise şöyledir;

- Çalışmadaki tüm hedefleri sağlayan sistemin başarılması,

- Asenkron motorun parametre değişiminin gerçek zamanlı olarak hesaplandığı bir SCADA yazılımının gerçekleştirilmesi,

- Asenkron motorun eşdeğer devre parametrelerindeki değişimin motorun performansı üzerindeki etkisinin belirlenmesi

Çalışmada, kullanılan SCADA yazılımı istenilen doğrulukta sonuç elde edilemeyebilir ya da hesaplama işlemi istenilen zamanda gerçekleştirilemeyebilir. Bu durumda doğruluğu artırmak için yapay zeka teknolojisi ya da sezgisel algoritmalardan faydalanılabilir. Böylece sistemin doğruluğu ve hızı artırılabilecektir.

Donanımsal olarak sorun çıkması durumunda asenkron motorun çalışma verilerinin okunması için kullanılan güç analizatörünün yerine sisteme akım ve gerilim sensörleri dahil ederek verilerin daha kısa sürede ve doğrıulukta elde edilebileceği bir tasarıma sistem dönüştürülebilir.

\section{Sonuç}

$\mathrm{Bu}$ çalışmadan elde edilecek sonuçların, farklı bilimsel ve teknolojik alanlarda kullanılabilme özelliği taşımaktadır. Proje sonucunda elde edilecek veriler ile asenkron motorla ilgili yeni projelerin geliştirilmesine temel oluşturacağı düşünülmektedir. Proje kapsamında gerçekleştirilmesi planlanan sistemin, asenkron motor performans parametre değerlerinin belirlenmesinde, imalat 
sanayisine teknolojik katkı sağlayacağı ve motordan maksimum verim elde ederek ülke ekonomisine katkı sağlayacağı düşünülmektedir.

Bu çalışma ile dört farklı konuda gelişmeler sağlanması beklenmektedir.

1. Çalışma sonucu motorun parametre değerleri gerçek zamanlı olarak belirlenebicek ve bu veriler arasında bir karşılaştırma yapılarak farklı güçlerdeki asenkron motorların parametre değişimleri değerlendirilebilecektir.

2. Bu çalışmadan elde edilen verilerle bundan sonra bu konu hakkında yapılacak çalışmalara bir kaynak özelliği taşıyacaktır. Ayrıca asenkron motorun modellenmesine yeni bir ışık oluşturacaktır. Bu da hem motor tasarımı hemde sürücü tasarımında önemli bir katkı sağlayacaktır.

3. Bu çalışma ile elde edilecek bilgi birikimi ve geliştirilen asenkron motor hız kontrol yöntemiyle farklı uygulamalarda da 'tezgah/makine/sistem durum tespiti ve önceden hata tahmini' amacıyla kullanılabilecek sistemlerdeki asenkron motorların etkin bir şekilde kontrol edilmesi mümkün olabilecektir. Bu gelişmelerin, endüstriyel alanda da yenilik getireceği ve kullanım alanı bulacağ açıktır.

Gerçekleştirilen bu çalışmada AC servo motorun kontrolü SCADA ile gerçekleştirilmiştir. Gerçekleştirilen SCADA sistemi ile AC Servo motor kullanılarak istenilen derecede, istenilen hızda ve istenilen sayıda hareketin gerçekleştirilmesi sağlanmıştır. Bu sistem amacına uygun olacak ve gücü yeterli olabilecek her sistemde kullanılabilir.

\section{Teşekkür}

Bu çalışma Konya Teknik Üniversitesi ve Selçuk Üniversitesi Bilimsel Araştırma Koordinatörlüğü 18401098 numaralı proje ile desteklenmiştir.

\section{Kaynaklar}

Aminu, M. (2019). A parameter estimation algorithm for induction machines using Artificial Bee Colony (ABC) optimization. Nigerian Journal of Technology, 38(1), 193-201.

Atkinson, D. J., Acarnley, P. P., \& Finch, J. W. (1991). Observers for induction motor state and parameter estimation. IEEE Transactions on industry applications, 27(6), 1119-1127.

Boglietti, A., Cavagnino, A., \& Lazzari, M. (2010). Computational algorithms for induction-motor equivalent circuit parameter determination-Part I: Resistances and leakage reactances. IEEE Transactions on Industrial Electronics, 58(9), $3723-3733$.

Cao, R., Lu, M., Jiang, N., \& Cheng, M. (2019). Comparison Between Linear Induction Motor and Linear Flux-switching PermanentMagnet Motor for Railway Transportation. IEEE Transactions on Industrial Electronics.

Cherifi, D., \& Miloud, Y. (2019). Online Stator and Rotor Resistance Estimation Scheme Using Sliding Mode Observer for Indirect Vector Controlled Speed Sensorless Induction Motor. American Journal of Computer Science and Technology, 2(1), 1-8.

Cui, M., Khodayar, M., Chen, C., Wang, X., Zhang, Y., \& Khodayar, M. E. (2019). Deep Learning Based Time-Varying Parameter Identification for System-Wide Load Modeling. IEEE Transactions on Smart Grid.

Dolinar, D., De Weerdt, R., Belmans, R., \& Freeman, E. (1997). Calculation of two-axis induction motor model parameters using finite elements. IEEE Transactions on Energy Conversion, 12(2), 133-142.

Gastli, A. (1999). Identification of induction motor equivalent circuit parameters using the single-phase test. IEEE Transactions on Energy Conversion, 14(1), 51-56.

Haque, M. (2008). Determination of NEMA design induction motor parameters from manufacturer data. IEEE Transactions on Energy Conversion, 23(4), 997-1004.

Jabbour, N., \& Mademlis, C. (2018). Online parameters estimation and autotuning of a discrete-time model predictive speed controller for induction motor drives. IEEE Transactions on Power Electronics, 34(2), 1548-1559.

Matsuo, T., \& Lipo, T. A. (1985). A rotor parameter identification scheme for vector-controlled induction motor drives. IEEE Transactions on industry applications(3), 624-632.

Mirafzal, B., Skibinski, G. L., \& Tallam, R. M. (2009). Determination of parameters in the universal induction motor model. IEEE Transactions on industry applications, 45(1), 142-151.

Moreira, A. F., Lipo, T. A., Venkataramanan, G., \& Bernet, S. (2002). High-frequency modeling for cable and induction motor overvoltage studies in long cable drives. IEEE Transactions on industry applications, 38(5), 1297-1306.

Nangsue, P., Pillay, P., \& Conry, S. E. (1999). Evolutionary algorithms for induction motor parameter determination. IEEE Transactions on Energy Conversion, 14(3), 447-453.

Pedra, J. (2008). On the determination of induction motor parameters from manufacturer data for electromagnetic transient programs. IEEE Transactions on Power Systems, 23(4), 1709-1718.

Pedra, J., \& Corcoles, F. (2004). Estimation of induction motor double-cage model parameters from manufacturer data. IEEE Transactions on Energy Conversion, 19(2), 310-317.

Shaw, S. R., \& Leeb, S. B. (1999). Identification of induction motor parameters from transient stator current measurements. IEEE Transactions on Industrial Electronics, 46(1), 139-149.

Toliyat, H. A., Levi, E., \& Raina, M. (2003). A review of RFO induction motor parameter estimation techniques. IEEE Transactions on Energy Conversion, 18(2), 271-283. 
Ursem, R. K., \& Vadstrup, P. (2003). Parameter identification of induction motors using differential evolution. Paper presented at the The 2003 Congress on Evolutionary Computation, 2003. CEC'03.

Yamamoto, S., Hirahara, H., Tanaka, A., \& Ara, T. (2018). A simple method to determine double-cage rotor equivalent circuit parameters of induction motors from no-load and locked-rotor tests. IEEE Transactions on industry applications, 55(1), 273282.

Zhang, D., Liu, T., Zhao, H., \& Wu, T. (2019). An Analytical Iron Loss Calculation Model of Inverter-fed Induction Motors Considering Supply and Slot Harmonics. IEEE Transactions on Industrial Electronics.

İnternet Kaynakları

1. https://www.siemens.com.tr/sinamicsg120 (adresinden Haziran, 2019 tarihinde alınmıştır)

2. https://www.elektrikport.com/teknik-kutuphane/plc-s7-1200-nedir/15172\#ad-image-2 (adresinden Haziran, 2019 tarihinde alınmıştır)

3. http://makrootomasyon.com.tr/6av2123-2gb03-0ax0/ (adresinden Haziran, 2019 tarihinde alınmıştır)

4. $\quad$ https://www.elit.ee/shelf.do?cmd=iv\&pid=6ES7231-5PA30-0XB0 (adresinden Haziran, 2019 tarihinde alınmıştır)

5. $\quad$ http://www.inverter-plc.net/sens\%C3\%B6rler/pt100.html (adresinden Haziran, 2019 tarihinde alınmıştır)

6. https://www.elektrikde.com/encoder-nedir-kullanim-alanlari/ (adresinden Haziran, 2019 tarihinde alınmıştır) 